\title{
SISTEM KENDALI OTOMATIS PANEL PENERANGAN LUAR MENGGUNAKAN TIMER THEBEN SUL 181 H DAN ARDUINO UNO R3
}

\author{
Sonny Rumalutur, ST.,MT, dan Ir. Johanes Ohoiwutun, MT \\ Politeknik Katolik Saint Paul Sorong \\ Email : sonny_r@poltekstpaul.ac.id; johnohoiwutun@poltekstpaul.ac.id
}

\begin{abstract}
Abstrak
Penerangan luar menggunakan timer dan arduino uno dan cara pemungsian alat ini ialah dengan sistem menghidupkan dan mematikan lampu dengan cara otomatis alat diatur sesuai dengan waktu yang kita inginkan sesuai dengan kebutuhan. Timer bisa disesuikan waktunya dengan cara menggunakan siripnya agar waktu bisa disesuikan dengan yang diinginkan dibuat manual ataupun auto dengan cara penggunaannya. Sedangkan Arduino Uno merupakan perangkat lunak yang berfungsi untuk mengupload program dengan hanya menekan tombol upload di software IDE program sketch pada Software arduino, Arduino diberkan progaram agar bisa menghidupkan lampu sesuai keinginan kita.
\end{abstract}

Kata kunci : Timer theben SUL 181H, Arduino uno, Kontaktor, Trafo BHL 250 Watt, Selektor switch.

\section{PENDAHULUAN}

\subsection{Latar Belakang}

Penerangan jalan umum atau disebut juga dengan penerangan pejalan kaki dan pengguna kendaraan merupakan suatu insfrastruktur bagi kehidupan masyarakat di malam hari, beberapa keuntungan dari penerangan jalan umum mendukung aktifitas masyarakat dimalam hari meningkatkan keselamatan dan kenyamanan pengendara, untuk keamanan lingkungan dan mencegah kriminalitas di setiap tempat pengguna jalan.

Lampu penerangan jalan merupakan bagian dari bangunan pelengkap jalan yang dapat diletakkan (dipasang dikiri atau dikanan jalan) dan atau ditengah (dibagian badan jalan sisi medan) yang digunakan untuk menerangi jalan maupun lingkungan sekitarnya dan menghindari diri dari kecelakaan salah satunya seperti jalan yang berlubang agar pengendara bisa menghindari terjadinya sebuah kecelakaan.

\subsection{Perumusan Masalah}

Dari latar belakang yang disampaikan diatas, maka perumusan masalahnya adalah bagaimana membuat Membuat Trainer Penerangan Luar dengan menggunakan mikrokontroler Arduino Uno dan timer theben SUL $181 \mathrm{~h}$ sistem agar dapat berfungsi dengan baik.

\subsection{Tujuan}

Tujuan dari penelitian ini adalah agar dapat membuat Rancang Bangun Modul Trainer Penerangan Luar menggunakan timer theben SUL $181 \mathrm{~h}$ dan arduino uno Rev 1.3.

\section{LANDASAN TEORI}

\subsection{Timer theben SUL $181 \mathrm{~h}$}

Timer theben sul $181 \mathrm{~h}$ ini sama seperti jam pada umumnya, kita bisa menyetel timer menurut yang kita inginkan alat ini juga mempunyai jarum dan angka pada lingkarannya, apa bila angka tidak sesuai, maka kita bisa menyetel pada putaran yang berada dikiri atas, tetapi cara menyetelnya Cuma 1 putaran saja,karena untuk memutar balik cuman tdk bisa lagi hanya 1 arah, 
kemudian tombol bawah hanya menentukan apa timer switch tersebut mau digunakan manual apa dengan menggunkan waktu yang sudah kita tentukan.

\subsection{Arduino uno Rev 1.3}

Arduino Uno Rev.1.3 adalah board berbasis mikrokontroler pada ATMega 328 . Board ini memiliki 14 digital input / ouput pin (dimana 6 pin dapat digunakan sebagai ouput PWM), 6 input analog, $16 \mathrm{MHz}$ osilator kristal, koneksi USB, jack listrik dan tombol reset. Pin pin ini berisi semua yang diperlukan untuk mendukung mikrokontroler, hanya terhubung ke komputer dengan kabel USB atau baterai untuk menggunakannya.

Arduino Uno Rev.1.3 dapat diaktifkan melalui koneksi USB atau dengan catu daya eksternal. arduino dapat beroperasi pada pasokan daya dari $7-12$ volt. Jika diberikan dengan kurang dari $7 \mathrm{~V}$, bagaimanapun, pin $5 \mathrm{~V}$ dapat menyeluplai kurang dari 5 volt dan board mungkin tidak stabil. Jika menggunakan lebih dari $12 \mathrm{~V}$, regulator bisa panas dan merusak board. Rentang yang dianjurkan adalah $7 \mathrm{~V}$ $12 \mathrm{~V}$.

PWM : 3,5,6,9,10, dan 11. Menyediakan 8bit output PWM dengan analogWrite() fungsi.

\subsection{Kontaktor LC1D09M7}

Penggunaan kontaktor listrik dalam sistem kontrol maupun sistem pendistribusian listrik sangat banyak manfaatnya, terutama dalam membantu sistem kontrol listrik maupun aplikasi sistem. Dahulu kontaktor berukuran besar dikarenakan bekerja dalam range arus besar, dan saat ini mulai banyak di temukan kontaktor dalam ukuran kecil.

Untuk kontaktor dibedakan dari jenis tegangan kerjanya $(24 \mathrm{~V}, 32 \mathrm{~V}, 220 \mathrm{~V}$ dst)tegangan ini dibutuhkan untuk menggerakan Coil yang ada di dalam kontaktor. Kegunaan kontaktor ada yang digunakan untuk keperluan pengoprasian motor atau pun hanya di gunakan dalam rangkaian kontrol yang terdapat di dalam mesin-mesin industri. setiap kontaktor di lengkapai dengan kontak relay bantu
(NO/Normaly Open/no.13-14) dan (NC/Normaly Close/no. 21-22)) selain kontak utama( 1-2, 3-4, 5-6), pada saat coil (no. A1-A2) kontaktor mendapatkan tegangan sehingga mengalirkan arus yang mengubah coil menjadi medan magnet dan menarik spul menekan kontaktor, sehingga yang awal posisinya terbuka menjadi tertutup begitu jugan degan relay pembantuan lainya.

Penggunaan kontaktor dalam waktu lama di butuhkan perawatan yang intensif mengingat peralatan tersebut selalu bergerak (Terbuka/ Tertutup) sehingga di takutkan dapat menyebabkan korosi, terdapat debu, karat pada bagian yang terbuka sehingga dapat menyebabkan percikan api akibat debu atau pun meleleh pada material yang bergerak akibat panas yang tidak merata.

\section{METODOLOGI KEGIATAN DAN PERANCANGAN SISTEM}

\subsection{Perancangan Model Sistem}

Untuk merancang bangun Modul menggunakan theben SUL $181 \mathrm{~h}$ dan arduino uno Rev 1.3, diperlukan langkah-langkah sebagai berikut :

1. Perancangan tata letak atau dudukan dari pada bangun modul serta rangkaianrangkaian yang ada pada Modul Trainer Penerangan seperti gambar berikut :

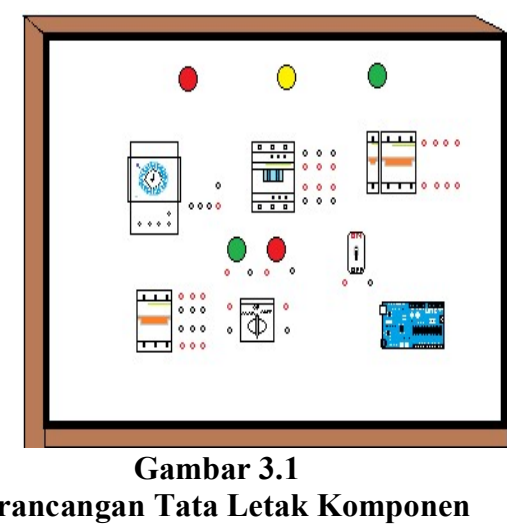

2. Perancangan papan trainer yang digunakan untuk meletakan komponen dan rangkaian terbuat dari mika akrelik dengan ukuran sebagai berikut:

Panjang Trainer $=50 \mathrm{~cm}$

Lebar Trainer $=55 \mathrm{~cm}$

Tinggi Trainer $=70 \mathrm{~cm}$ 


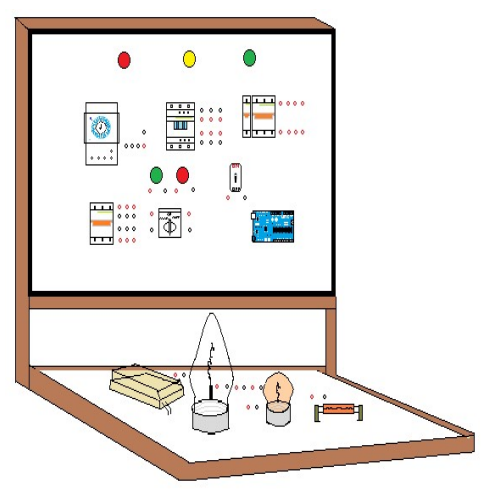

Gambar 3.2 Trainer Perancangan

3. Hasil perancangan trainer.

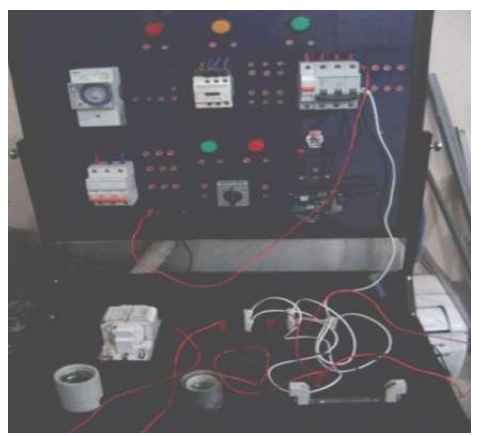

Gambar 3.3

Hasil Rancang Bangun Modul Trainer Penerangan Luar

\subsection{Perancangan Perangkat Keras}

Perancangan perangkat keras untuk pintu otomatis digambarkan dalam bentuk diagram blok parancangan rangkaian antar muka.

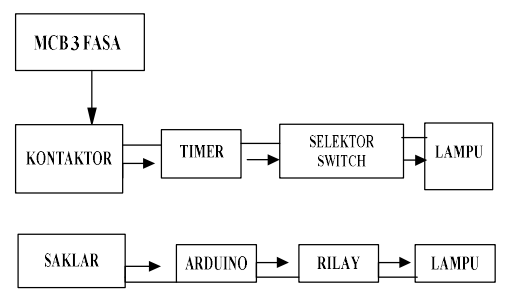

Gambar 3.4

Diagram Blok Perancangan Rangkaian perangkat keras

Dari gambar diagram blok sistem diatas, peneliti dapat menjelaskan cara kerja dari diagram blok perancangan rangkaian antar muka sebagai berikut:

Sewaktu menggunakan sistem 3 phasa akan menggunakan timer theben SUL $181 \mathrm{~h}$ yang difungsikan untuk menghidupkan lampu yang kita inginkan dengan cara otomatis dengan cara menyetel timer tersebut kearah waktu yang kita inginkan sedangkan apa bila menggunakan sistem arduino arduino uno Rev 1.3 kita bisa mengaktifkan atau menghidupkan lampu dengan cara mengisi program dan secara otomatis menyalakan lampu sesuai dengan waktu yang telah kita masukkan.

\subsection{Perancangan Perangkat Lunak}

Flowchart kerja untuk sistem menyalakan lampu secara otomatis sebagai berikut:

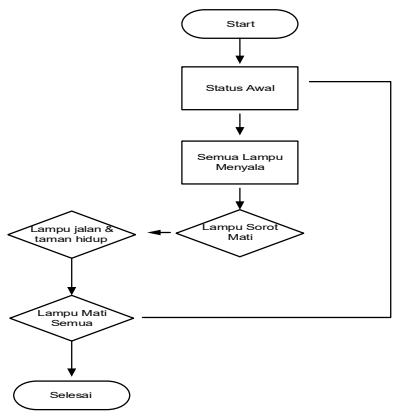

Gambar 3.5

Flowchart kerja pada penerangan luar

\section{Sistem Kerja Pada Modul Trainer}

Pada saat di beri tegangan ke arduino uno Rev 1.3 lalu program bekerja menghidupkan lampu dan beberapa saat kemudian lampu yang lain mati secara bergantian, Begitu pun apa bila kita menggunakan sisitem Timer Theben SUL $181 \mathrm{~h}$, Tetepi apa bila menggunakan timer bisa diaktifkan secara Manual atau Auto fungsi dari Auto atau Manual agar memudahkan kita menghidupkan, dengan menyetel waktu dan secara otomatis nyala sedangkan Manual cuma mengarahkan selektor menuju manual lampu pun menyala.

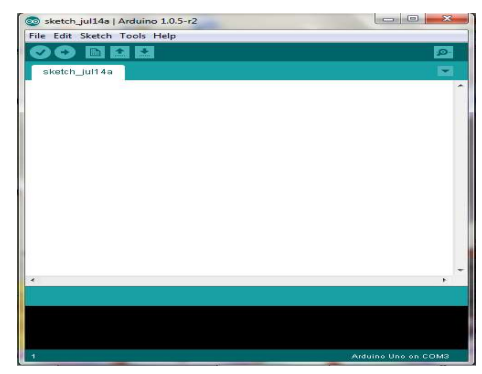

Gambar 3.6 Tampilan IDE Program Sketch 


\subsection{Perancangan Pengujian Sistem}

Dari hasil prancangan prangkat keras dan prangkat lunak, kemudian kami lakukan pengujian disetiap sistemnya pada perangkatperangkat tersebut.

Perancangan pengujian sistem:

a. Timer Theben SUL $181 \mathrm{~h}$

b. Arduino uno Rev 1.3

c. Kontaktor LC1D09M7

d. Selektor Switch

e. Saklar

f. MCB

g. Relay

h. Lampu

\section{PENGUJIAN PEMBAHASAN}

ALAT DAN

\subsection{Pengujian Program Dari Komputer Ke Mikrokontroller Arduino Uno Rev 1.3}

Program ini akan berkomunikasi dari komputer ke mikrokontroller dengan berbagai jenis tampilan program yang dapat di transfer ke Mikrokontroller.

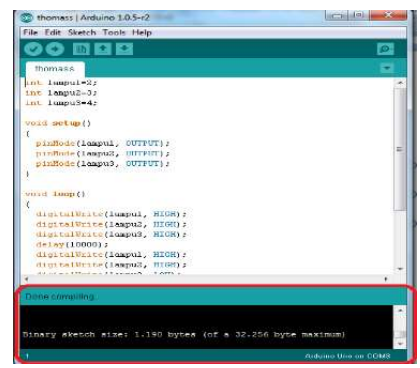

Gambar 4.1 Tampilan Sketch Arduino Saat Program Valid

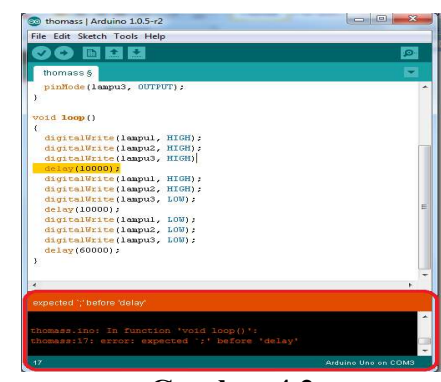

Gambar 4.2

Tampilan Sketch Arduino Saat Program Invalid

Tampilan dari kedua gambar diatas merupakan tampilan pengujian program yang terjadi jika ingin mengetahui apabila program yang di buat itu valid atau invalid. Apabila tampilan dari pengujian program yang di uji, dibagian kiri bawah dari sketch pemrograman bertuliskan done compilling seperti pada gambar 4.1 diatas, berarti tidak ada kesalahan yang terjadi pada saat program, dan bisa langsung diupload ke arduino uno Rev.1.3, namun jika pemrograman terjadi kesalahan atau invalid, pada bagian kiri bawah dari sketch pemrograman akan tampil komentar berwarna orange seperti pada gambar 4.2 diatas, dan programpun tidak bisa diupload ke mikrokontroller arduino uno.

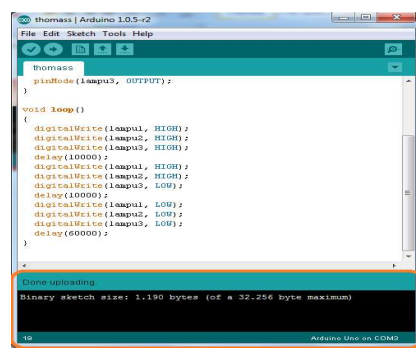

Gambar 4.3

Tampilan Sketch Arduino Saat Program Berhasil Di Upload Ke Arduino Uno Rev.1.3

Jika komunikasi serial berhasil, pada dibagian kiri bawah dari sketch pemrograman akan bertuliskan done uploading seperti yang ditunjukan pada gambar 4.3 di atas.

\subsection{Pengujian Port I/O Arduino Uno Rev.1.3}

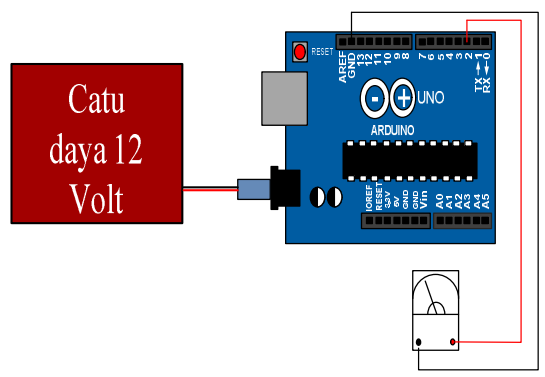

Gambar 4.4

Rangkaian Pengujian Port Pada rancang bangun modul trainer penerangan luar menggunakan timer dan arduino 
Pengujian Port I/O arduino uno Rev.1.3 dapat dilakukan dengan cara mengukur tegangan keluaran pada portnya. Untuk melakukan pengujian pada Port I/O arduino uno Rev.1.3 dilakukan langkah-langkah sebagai berikut:

1. Menyambungkan arduino uno Rev.1.3 ke komputer dengan menggunakan Jalur komunikasi USB serial untuk arduino uno Rev.1.3.

2. Memberikan tegangan 7-12 VDC untuk mengaktifkan arduino uno Rev.1.3 atau bisa langsung menghidupkan arduino uno Rev.1.3 dengan cara menyambungkan Jalur komunikasi USB serial untuk arduino uno Rev.1.3.

3. Setelah arduino uno Rev.1.3 aktif, transfer program yang telah di buat di software arduino, dengan cara klik tanda panah yang ada di kanan atas pada software arduino atau bisa langsung menekan Ctrl-U.

4. Ukurlah semua keluaran portnya mulai dari port 0 sampai dengan port 13 dengan menggunakan Avometer. Jika semua port mengeluarkan tegangan sebesar 5 VDC maka Arduino Uno Rev 1.3 itu dalam kondisi baik.

\section{Hasil Pengujian Port I/O Arduino Uno Rev 1.3}

Adapun tabel hasil pengukuran yang telah diuji pada pengujian Port I/O Arduino Uno Rev 1.3 adalah sebagai berikut:

Tabel 4.1 Pengukuran Tegangan Pada Pengujian Port Arduino Uno Rev 1.3

\begin{tabular}{|c|c|c|c|c|}
\hline $\begin{array}{l}\text { N } \\
\text { o }\end{array}$ & $\begin{array}{c}\text { Titik } \\
\text { Penguj } \\
\text { ian }\end{array}$ & $\begin{array}{c}\text { Hasil } \\
\text { Pengukur } \\
\text { an }\end{array}$ & $\begin{array}{c}\text { Hasil } \\
\text { Sebenar } \\
\text { nya }\end{array}$ & $\begin{array}{c}\% \\
\text { Error }\end{array}$ \\
\hline 1 & Port 1 & 4,91 VDC & 5 VDC & $\begin{array}{c}0,018 \\
\%\end{array}$ \\
2 & Port 2 & 4,91 VDC & 5 VDC & $\begin{array}{c}0,018 \\
\%\end{array}$ \\
\hline
\end{tabular}

Presentase Kesalahan (\% Error)

$\%$ Error $=$

$$
\left|\frac{\sum \text { Hasil Seharusnya }-\sum \text { Hasil Pengukuran }}{\sum \text { Hasil Seharusnya }}\right| \times
$$

$$
100 \% \text {.......... (i) }
$$

1. $\%$ Error $=\left|\frac{5-4,91}{5}\right| \times 100 \%=0,018 \%$

2.

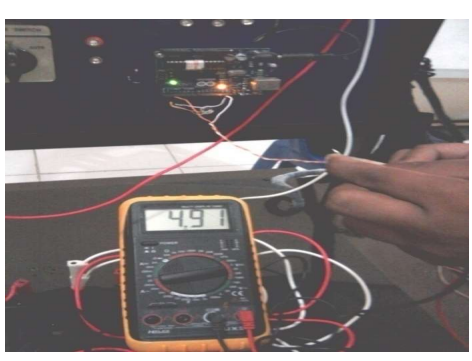

Gambar 4.5

Hasil Pengukuran Pada Port Arduino

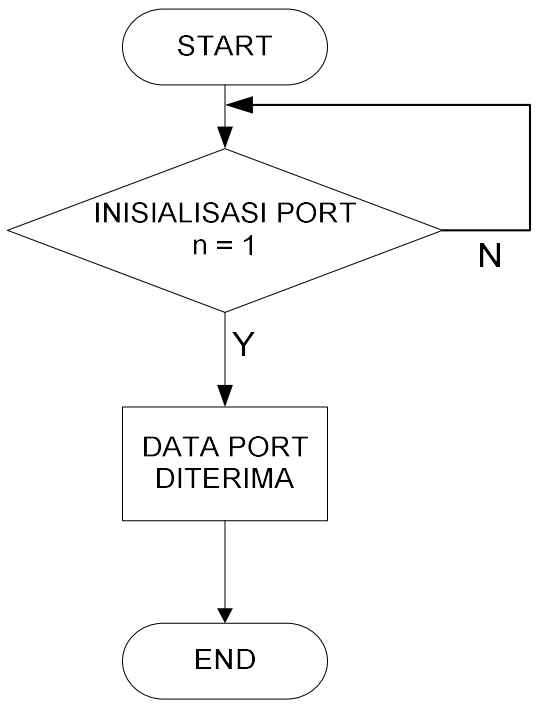

Gambar 4.6

Flowchart Program Pengujian Port

\subsection{Pengujian Rangkaian Pada Lampu 1}

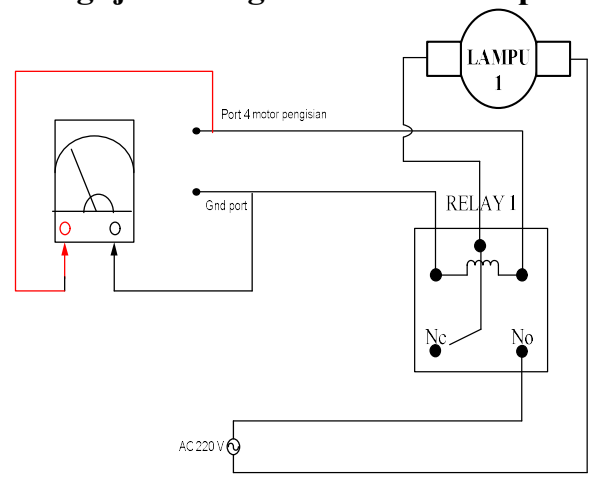

Gambar 4.7

Rangkaian Pengujian Untuk Lampu 1

Penjelasan cara kerja rangkaian diatas adalah ketika Port 2, 3 dan 4 High, maka kontak No pada Relay akan terhubung sehingga 
membuat 3 buah Lampu menyala selang beberapa detik kemudian lampu Halogen mati pada port 4 dan kedua lampu lainnya masih menyala / aktif pada port 2 dan 3, dan beberapa detik kemudian lampu lainnya juga ikut mati

Pada Rangkaian yang telah dibuat menjelaskan apa bila kita memakai Relay pada port 4 lampu yang digunakan adalah lampu halogen yang akan digunakan pada lapangan tennis yang penggunaanya berbeda dengan lampu keduanya lampu halogen hanya digunakan pada saat lapangan terpakai atau saat digunakan.

Cara menguji rangkaian lampu on pada port 4 menunjukan pengukuran pada Relay dengan cara kabel merah $(+)$ pada avometer ke relay kaki coil kemudian kabel hitam (-) pada avometer ke kaki relay coil ground. Dan amati hasil yang akan terjadi apabila rangkaian lampu aktif maka rangkaian tersebut dalam kondisi baik.

Pengujian rangkaian lampu tidak hanya dengan mengamati hasil yang terjadi, namun pengukuran pun dilakukan agar dapat memastikan apakah tegangan input dan output keluaran sudah sesuai dengan hasil yang seharusnya.

\section{Hasil Pengujian Rangkaian Lampu 1}

Adapun tabel hasil pengukuran yang telah diuji pada rangkaian driver lampu 1adalah sebagai berikut :

Tabel 4.2 Pengukuran Tegangan Pada Rangkaian Lampu 1

Presentase Kesalahan (\% Error)

$\%$ Error $=\left|\frac{\text { Hasil Seharusnya }- \text { Hasil Pengukuran }}{\text { Hasil Seharusnya }}\right| \times$

$100 \%$ (iii)

1. $\%$ Error $=|(0-0) / 0| \times 100 \%=0 \%$

2. $\%$ Error $=(5-3,57) / 5 \mid \times 100 \%=0,286 \%$

3. $\%$ Error $=|(220-202) / 220| \times 100 \%=0,081 \%$

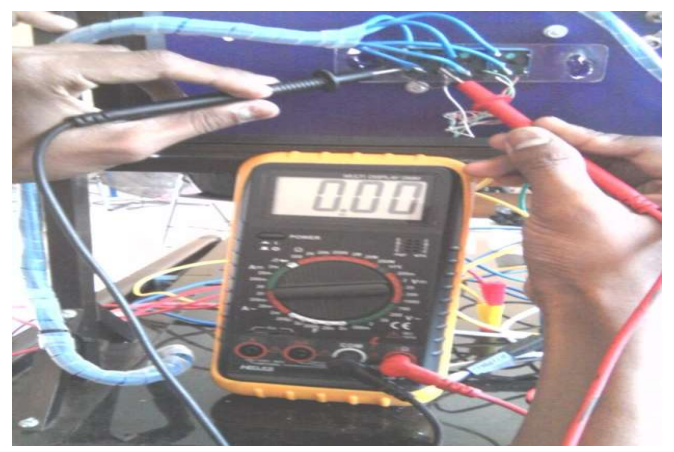

Gambar 4.8

Pengukuran Pada Saat Sebelum Lampu Nyala

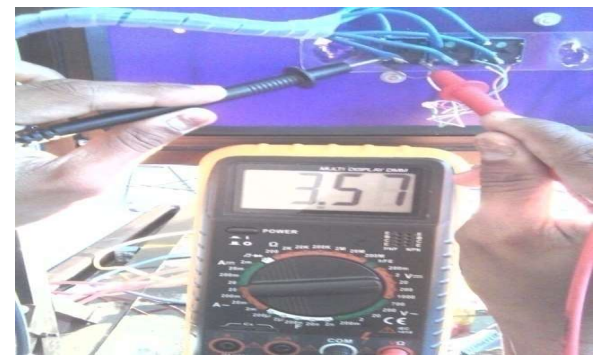

Gambar 4.9

Pengukuran Pada Saat Lampu 1 menyala

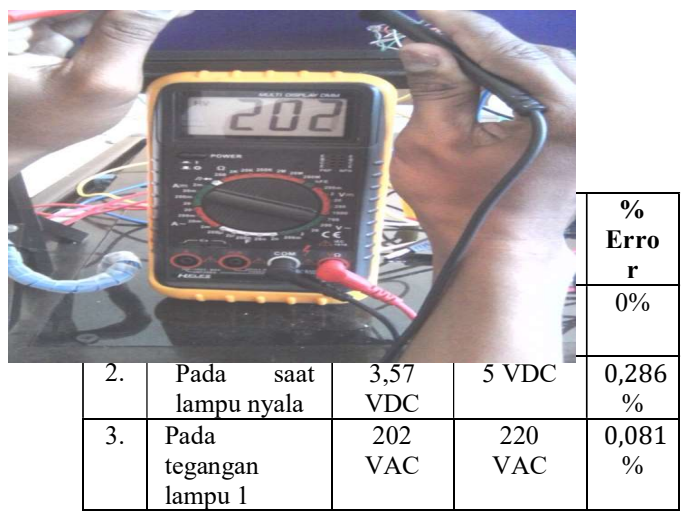

Gambar 4.10

Pengukuran Tegangan Lampu AC 


\subsection{Pengujian Keseluruhan Rangkaian pada lampu jalan}

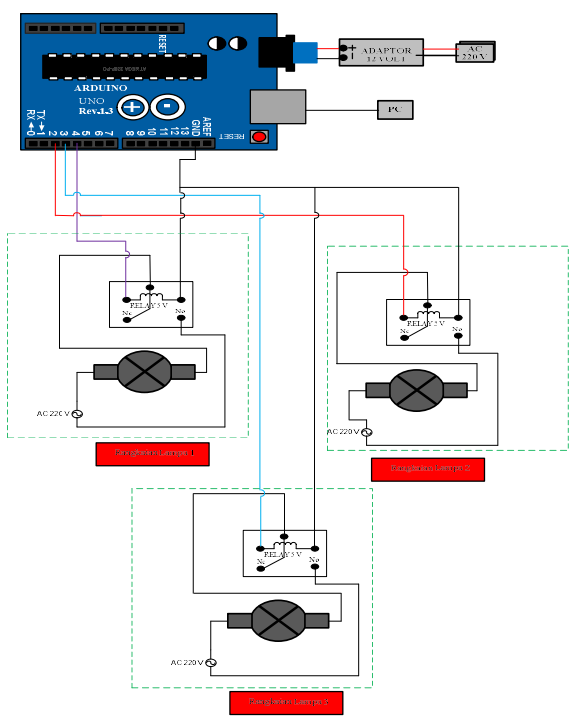

Gambar 4.11

Wiring Diagram Keseluruhan Rangkaian

Pada pengujian ini dilakukan dengan cara menjalankan semua sistem keseluruhan mulai dari memasukkan tegangan ke Arduino Uno, maka arduino uno akan memberikan tegangan pada relay atau port yang ada pada rangkaian setelah mendapatkan tegangan lampu yang akan kita gunakan sesuai dengan waktu yang sudah diprogram.

Apabila rangkaian semua telah berfungsi maka pengukuran pada setiap port dilakukan dan mengukurnya sebelum digunakan dan pada saat semua lampu sudah berfungsi.

\section{Hasil Pengujian Rangkaian}

Adapun tabel hasil pengukuran yang telah diuji pada rangkaian lampu adalah sebagai berikut :

Tabel 4.3

Pengukuran pengujian Tegangan Pada Rangkaian lampu 3

Presentase Kesalahan (\% Error)

$\%$ Error $=$

$\left|\frac{\text { Hasil Seharusnya - Hasil Pengukuran }}{\text { Hasil Seharusnya }}\right| \times 100 \%$ (iii)

1. $\%$ Error $=\left|\frac{0-0}{0}\right| \times 100 \%=0 \%$

2. $\%$ Error $=\left|\frac{220-198}{220}\right| \times 100 \%=0,01$

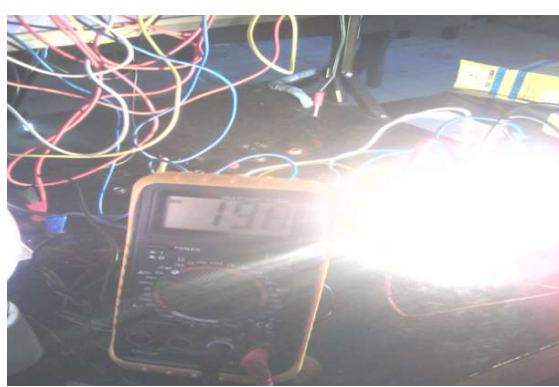

Gambar 4.12

Gambar rangkaian pengujian

Penjelasan cara kerja rangkaian diatas adalah pada saat kita melakukan pengetesan kita masukkan tegangan ke Modul Trainer Penerangan setelah lampu dan timer sudah berfungsi dengan baik maka kita lakukan pengukuran langsung pada keluaran MCB.

Cara menguji rangkaian lampu pada posisi on pengukuran pada keluaran MCB dengan cara kabel merah $(+)$ pada avometer ke tegangan kemudian kabel hitam (-) pada avometer ke Nol. Dan amati hasil yang akan terjadi apabila pengukuran langsung pada keluaran tegangan aktif maka rangkaian tersebut dalam kondisi baik.

Pengujian rangkaian keluaran arus tidak hanya dengan mengamati hasil yang terjadi, namun pengukuran pun dilakukan agar dapat memastikan apakah tegangan input dan output keluaran sudah sesuai dengan hasil yang seharusnya.

Adapun tabel hasil pengukuran yang telah diuji pada saat pengujian keseluruhan rangkaian Penerangan luar dengan sistem otomatis adalah sebagai berikut:

Tabel 4.4

Pengukuran Tegangan Keseluruhan Rangkaian

\begin{tabular}{|c|c|c|c|c|}
\hline $\mathbf{N}$ & $\begin{array}{c}\text { Titik } \\
\text { Pengujian }\end{array}$ & $\begin{array}{c}\text { Hasil } \\
\text { Penguku } \\
\text { ran }\end{array}$ & $\begin{array}{c}\text { Hasil } \\
\text { Sebena } \\
\text { rnya }\end{array}$ & $\begin{array}{c}\% \\
\text { Error }\end{array}$ \\
\hline 1. & $\begin{array}{l}\text { Pada saat } \\
\text { tidak nyala }\end{array}$ & 0 & 0 & $0 \%$ \\
\hline 2. & $\begin{array}{l}\text { Pada saat } \\
\text { lampu nyala }\end{array}$ & 198 VDC & $\begin{array}{c}220 \\
\text { VDC }\end{array}$ & $0,01 \%$ \\
\hline
\end{tabular}




\begin{tabular}{|c|c|c|c|c|}
\hline No & $\begin{array}{l}\text { Titilk } \\
\text { Pengujian }\end{array}$ & $\begin{array}{l}\text { Hasil } \\
\text { pengu } \\
\text { kuran }\end{array}$ & $\begin{array}{l}\text { Hasil } \\
\text { Sebenar } \\
\text { nya }\end{array}$ & $\begin{array}{l}\% \% \\
\text { Error }\end{array}$ \\
\hline 1 & $\begin{array}{l}\text { Pada gaat } \\
\text { tidak nyala }\end{array}$ & 0 & 0 & $0 \%$ \\
\hline 2 & $\begin{array}{l}\text { Pada gaat } \\
\text { lampu } \\
\text { nyala }\end{array}$ & $\begin{array}{l}3,57 \\
\text { VDC }\end{array}$ & $5 \mathrm{VDC}$ & $\begin{array}{l}0,286 \\
\%\end{array}$ \\
\hline 3 & $\begin{array}{l}\text { Pada } \\
\text { tegangan } \\
\text { lampu } 1\end{array}$ & $\begin{array}{l}202 \\
\text { VAC }\end{array}$ & $220 \mathrm{VAC}$ & $\begin{array}{l}0,081 \\
\%\end{array}$ \\
\hline 4 & $\begin{array}{l}\text { Pada saat } \\
\text { tidak nyala }\end{array}$ & 0 & 0 & $0 \%$ \\
\hline 5 & $\begin{array}{l}\text { Pada saat } \\
\text { lampu } \\
\text { nyala } \\
\end{array}$ & $\begin{array}{l}3,59 \\
\text { VDC }\end{array}$ & $5 \mathrm{VDC}$ & $\begin{array}{l}0,282 \\
\%\end{array}$ \\
\hline 6 & $\begin{array}{l}\text { Pada } \\
\text { tegangan } \\
\text { lampu } 2\end{array}$ & $\begin{array}{l}202 \\
\text { VAC }\end{array}$ & $220 \mathrm{VAC}$ & $\begin{array}{l}0,081 \\
\%\end{array}$ \\
\hline 7 & $\begin{array}{l}\text { Pada saat } \\
\text { tidak nyala }\end{array}$ & 0 & 0 & $0 \%$ \\
\hline 8 & $\begin{array}{l}\text { Pada saat } \\
\text { lampu } \\
\text { nyala }\end{array}$ & $\begin{array}{l}3,56 \\
\text { VDC }\end{array}$ & $5 \mathrm{VDC}$ & $\begin{array}{l}0,288 \\
\%\end{array}$ \\
\hline 9 & $\begin{array}{l}\text { Pada } \\
\text { tegangan } \\
\text { lampu } 3\end{array}$ & $\begin{array}{l}202 \\
\text { VAC }\end{array}$ & $220 \mathrm{VAC}$ & $\begin{array}{l}0,081 \\
\%\end{array}$ \\
\hline 10 & $\begin{array}{l}\text { Pada gaat } \\
\text { tidak nyala }\end{array}$ & 0 & 0 & $0 \%$ \\
\hline 11 & $\begin{array}{l}\text { Pada gaat } \\
\text { lampu } \\
\text { nyala }\end{array}$ & $\begin{array}{l}198 \\
\text { VDC }\end{array}$ & $220 \mathrm{VDC}$ & $0,01 \%$ \\
\hline 12 & $\begin{array}{l}\text { Pada gaat } \\
\text { tidak nyala }\end{array}$ & 0 & 0 & $0 \%$ \\
\hline 13 & $\begin{array}{l}\text { Pada gaat } \\
\text { pengukura } \\
n \text { amper }\end{array}$ & $\begin{array}{l}\text { 3,62 } \\
\text { Amper }\end{array}$ & 6 Amper & $\begin{array}{l}0,396 \\
\%\end{array}$ \\
\hline
\end{tabular}

Presentase Kesalahan (\% Error)

$\%$ Error $=$

$\left|\frac{\text { Hasil Seharusny - Hasil Pengukuran }}{\text { Hasil Seharusny }}\right| \times 100 \%$ (vii)

1. $\%$ Error $=\left|\frac{0-0}{0}\right| \times 100 \%=0 \%$

2. $\%$ Error $=\left|\frac{5-3,57}{5}\right| \times 100 \%=0,286 \%$

3. $\%$ Error $=\left|\frac{220-202}{220}\right| \times 100 \%=0,081 \%$

4. $\%$ Error $=\left|\frac{0-0}{0}\right| \times 100 \%=0 \%$

5. $\%$ Error $=\left|\frac{5-3,59}{5}\right| \times 100 \%=0,282 \%$

6. $\%$ Error $=\left|\frac{220-202}{220}\right| \times 100 \%=0,081 \%$

7. $\%$ Error $=\left|\frac{0-0}{0}\right| \times 100 \%=0 \%$

8. $\%$ Error $=\left|\frac{5-3,56}{5}\right| \times 100 \%=0,288 \%$

9. $\%$ Error $=\left|\frac{220-202}{220}\right| \times 100 \%=0,081 \%$

10. $\%$ Error $=\left|\frac{0-0}{0}\right| \times 100 \%=0 \%$

11. $\%$ Error $=\left|\frac{220-202}{220}\right| \times 100 \%=0,01 \%$

12. $\%$ Error $=\left|\frac{0-0}{0}\right| \times 100 \%=0 \%$

13. $\%$ Error $=\left|\frac{220-202}{220}\right| \times 100 \%=0,369 \%$

\section{PENUTUP}

\subsection{Kesimpulan}

1. Pada saat pengujian pada lampu jalan, lampu 1 dihidupkan secara otomatis lalu lampu 2 dan 3 ikut menyala, dan apa bila timer berfungsi pada waktu yang sudah disesuaikan maka lampu 1 mati secara otomatis lampu 2 dan 3 menunggu waktu yang sudah disesuaikan.

2. Pada lampu penerangan jalan dapat dijalankan dengan sistem microkontroler dan sistem manual dengan mengunakan timer.

3. Untuk dapat menjalankan sebuah lampu penerangan secara otomatis membutuhkan relay 5 volt untuk sebagai rangkaian driver, agar sebagai pengunci pada lampu dan lampu pun akan hidup dengan melalui sistem Mikrokontroller Arduino.

\subsection{Saran}

Adapun saran yang dapat diberikan pada saat menjalankan atau memungsikan trainer tersebut.

1. Dalam melakukan praktek pada modul trainer penerangan luar menggunakan timer theben sul $181 \mathrm{~h}$ dan arduino uno $\mathrm{r} 3$ perlu ketelitian dan kesabaran agar tidak terjadi kesalahan yang dapat menyebabkan kerusakan pada komponen-komponen tersebut.

2. Pada saat melakukan pengetesan alat / praktek sebaiknya lampu yang sangat harus dijaga adalah lampu jangan sampai terkena alat lain apalagi lampu halogen karena sangat sensitif untuk disentuh mudah putus.

3. Pemrograman untuk Arduino itu sudah dimasukkan sesuai dengan yang diinginkan, apabila ingin merubah waktu yang yang lebih tepat lagi maka harus dilakukan pemrograman ulang

\section{DAFTAR PUSTAKA}

Hajsardar, M., Borghei, S. M., Hassani, A. H., \& Takdastan, A. (2016). Simultaneous ammonium and nitrate removal by a modified intermittently aerated sequencing batch reactor (SBR) with 
multiple filling events. Polish Journal of Chemical Technology, 18(3), 72-80.

Mappa, A. (2018). SISTEM PARKIR CERDAS SEDERHANA BERBASIS ARDUINO MEGA 2560 Rev3. Electro Luceat, 4(1), 20-31.

Margolis, M. (2011). Arduino cookbook: recipes to begin, expand, and enhance your projects. " O'Reilly Media, Inc.".

Marquis, E. E. (1976). U.S. Patent No. 3,997,742. Washington, DC: U.S. Patent and Trademark Office.
Monk, S. (2014). Programming Arduino Next Steps: Going Further with Sketches. McGrawHill.

Tobi, M. D. (2018). DESAIN SISTEM PENGONTROLAN PINTU AIR OTOMATIS BERDASARKAN LEVEL KETINGGIAN AIR PADA KALI REMU SORONG PAPUA BARAT. Electro Luceat, 4(1), 43-51.

Tobi, M. D. (2015). RANCANG BANGUN ROBOT BERODA PEMADAM API MENGGUNAKAN ARDUINO UNO REV. 1.3. Electro Luceat, 1(1). 